\title{
A Week-long Study on Robot-Visitors Spatial Relationships during Guidance in a Sciences Museum
}

\author{
Marta Díaz \\ Technical University of \\ Catalonia \\ marta.diaz@upc.edu \\ Oriol Torres \\ PAL Robotics \\ oriol.torres@pal- \\ robotics.com
}

\author{
Dennys Paillacho \\ Escuela Superior Politécnica \\ del Litoral \\ dpaillac@espol.edu.ec \\ Jonathan González \\ PAL Robotics \\ jon.gonzalez@pal- \\ robotics.com
}

\author{
Cecilio Angulo \\ Technical University of \\ Catalonia \\ cecilio.angulo@upc.edu \\ Jordi Albo-Canals \\ La Salle BCN - Ramon Llull \\ University \\ jalbo@salle.url.edu
}

\begin{abstract}
In order to observe spatial relationships in social humanrobot interactions, a field trial was carried out within the CosmoCaixa Science Museum in Barcelona. The follow me episodes studied showed that the space configurations formed by guide and visitors walking together did not always fit the robot social affordances and navigation requirements to perform the guidance successfully, thus additional communication prompts are considered to regulate effectively the walking together and follow me behaviors.
\end{abstract}

\section{Categories and Subject Descriptors}

I.2 [Artificial Intelligence]: Robotics; D.2.8 [Software Engineering]: Complexity measures, Performance measures

\section{General Terms}

Human Factors

\section{Keywords}

social human-robot interaction, spatial relationships, proxemics behavior

\section{INTRODUCTION}

Guidance is one of the most useful services robots may deliver in public spaces as museums, exhibitions, malls, and tourist sites. Taking the role of guide, the robot not only provides people with appropriate information to make the visit a more enjoyable experience, but help them to get to intended destinations. The main difference between an informer or recommender robot and a robotic guide is that guidance in public spaces implies social navigation in a highly dynamic scenario. Robotic museum guides as MINERVA

Permission to make digital or hard copies of part or all of this work for personal or classroom use is granted without fee provided that copies are not made or distributed for profit or commercial advantage, and that copies bear this notice and the full citation on the first page. Copyrights for third-party components of this work must be honored. For all other uses, contact the owner/author(s). Copyright is held by the author/owner(s).

HRI'14, March 3-6, 2014, Bielefeld, Germany.

ACM 978-1-4503-2658-2/14/03.

http://dx.doi.org/10.1145/2559636.2559797.
[1] and ROBOVIE [2] have proven to be effective addressing people and keeping their attention, in spite of the highly challenging context. However, as far as we know, research on robotic guides has mainly focused on verbal and non-verbal communicative behaviors to improve the visitor experience, but no studies have been carried out to model spatial arrangements during guidance.

\section{SPATIAL RELATIONSHIPS IN HRI}

Service robots featured with walk around functionality must deal with crucial social navigation issues: how to move (i.e. speed, kind of movement and trajectories), where to perform and how to place (i.e. distance, position and orientation) to be unobtrusive, effective and socially congruent. Moreover, robots in shared spaces get involved in spatial relationships with people [3], [4]. Spatial relationships are a combination of distance, relative position and orientation that occur naturally whenever two or more people engage in an interaction [5] and convey significant and relevant social information and also define an interpersonal space for developing activity [3]. Promising attempts to optimize social robots spatial management in different scenarios (e.g. telepresence assistance at home) have been done applying models and knowledge from social psychology (i.e. proxemics, space formations, group walking patterns and crowd dynamics).

Studies in telepresence mobile robots have identified the management of spatial and orientation relationships between people and robot as a main issue in order to improve the quality of interaction. Based on Kendon's model, the authors identify different space formations or spatial patterns (e.g. vis a vis, side-by-side, L-shape, follow or ahead) according to the robot's role, the activities carried out and the spatial constraints, as well as individual variables such as familiarity with the agent [3]. An interesting conclusion is that when physical constraints in combination of navigational requirements unable the robot to maintain the convenient spatial behavior, it can compensate this situation with other interactive behaviors (e.g. verbally apologizing for inappropriate proximity or reducing the eye-contact) to maintain an overall degree of desired intimacy.

In the context of the robot taking the role of a guide in a museum the guidance is viewed as a highly demanding collaborative task that implies communicating intentions (i.e. robot offers the service, visitors select a destination and re- 


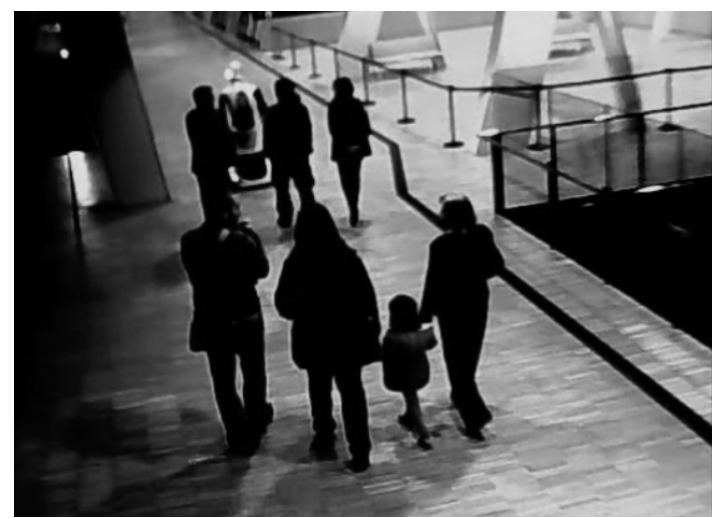

Figure 1: Robot guiding visitors

quest the bring me there function, the robot head towards the destination) and social navigation (i.e. walk together to the intended destination) (see Fig. 1). This group walking following a leader behavior implies complex space regulations (i.e. proximity management, spatial configurations) to allow guide and visitors group up and walk together effectively to a target destination. These space relationships during guidance must be at a time socially meaningful and compatible with the robot's navigation specifications (i.e. collision avoidance performance).

The present work addresses the identification and description of space relationships during guidance applying models from social psychology such as group walking [6] and crowd dynamics [7].

\section{THE FIELD TEST}

During 6 days the robot REEM walked around the CosmoCaixa Science Museum in an open space, providing information to visitors and offering the service to bring them to a particular location. The robot's performance and the guidevisitors interaction were observed and videorecorded for further analyses of visitors-guide communication and space relationships, and to evaluate the robustness of robot performance in the wild.

In the present study we focus specifically on the follow me behavior. In the context of guidance a follow me episode is defined as a walking group formation including the robot displacing together and forming typically any of these two spatial arrangements: walking along with (i.e. robot and people aligned side-by-side perpendicularly to the walking direction) or walking ahead (i.e. visitors follow the robot, see Fig.1).

91 episodes of follow me were observed. In almost all the cases a walking ahead formation was observed (see Table 1), where the robot leads the group and visitors follow behind. While this space arrangement is a natural disposition for following a leader in a high density groups [7] pose important constraints to communication and therefore to social cohesion between the guide robot and visitors during guidance. On the other hand, only 2 side-by-side spatial formations were observed during guidance and in both cases it was just two people interacting with the robot.
Table 1: Spatial relationships by group size

\begin{tabular}{lrrrrrrrrrr}
\hline & \multicolumn{1}{c}{ Group size } \\
& 1 & 2 & 3 & 4 & 5 & 6 & 7 & 8 & $9+$ & Total \\
\hline Leader-follower & 3 & 8 & 13 & 4 & 9 & 2 & 6 & 4 & 33 & 82 \\
Side by side & 0 & 2 & 0 & 0 & 0 & 0 & 0 & 0 & 0 & 2 \\
Unidentified & 0 & 0 & 0 & 1 & 1 & 0 & 1 & 0 & 4 & 7 \\
Total & 3 & 10 & 13 & 5 & 10 & 2 & 7 & 4 & 37 & 91 \\
\hline
\end{tabular}

\section{CONCLUSIONS}

From literature and from the observations gathered during the field test we can conclude that spatial arrangements create the social field for shared activity and thus influence the quality of human-robot interaction. The appropriateness of the space relationship is a key issue in collaborative activities as guidance that requires continuous communication (i.e. offering to bring, heading a destination) and mutual regulation (i.e. group walking together).

Spontaneous spatial arrangements during guidance may not be effective when confronted with robot's affordances and navigation specifications and therefore limit the system performance. However, group behavior could be anticipated -from social psychology and HRI models- and managed socially by the robot guide implementing new behaviors (e.g. awareness of group density) or through communication (e.g. asking kindly to clear off its way)

\section{ACKNOWLEDGMENTS}

This research was supported in part by the PATRICIA Research Project (TIN2012-38416-C03-01,03), funded by the Spanish Ministry of Economy and Competitiveness.

\section{REFERENCES}

[1] S. Thrun et al. MINERVA: A second- generation museum tour-guide robot. In IEEE International Conference on Robotics and Automation, vol 3, pp 1999-2005, 1999.

[2] M. Montemerlo, J. Pineau, N. Roy, S. Thrun, and V. Verma. Experiences with a mobile robotic guide for the elderly. In 18th National Conference on Artificial Intelligence, pp 587-592, Menlo Park, CA, USA, 2002.

[3] A. Kristoffersson, K. Severinson-Eklundh, and A. Loutfi. Measuring the quality of interaction in mobile robotic telepresence: A pilot's perspective. Int. J. Soc. Rob., 5(1):89-101, 2013.

[4] H. Hüettenrauch, K.S. Eklundh, A. Green, and E.A. Topp. Investigating spatial relationships in human-robot interaction. In IEEE/RSJ International Conference on Intelligent Robots and Systems, pp 5052-5059, 2006.

[5] P. Marshall, Y. Rogers, and N. Pantidi. Using f-formations to analyse spatial patterns of interaction in physical environments. In Proceedings of the ACM 2011 Conference on Computer Supported Cooperative Work, CSCW '11, pp 445-454, New York, NY, USA, 2011.

[6] M. Costa. Interpersonal distances in group walking. Journal of Nonverbal Behavior, 34(1):15-26, 2010.

[7] S. Bandini, A. Gorrini, L. Manenti, and G. Vizzari. Crowd and pedestrian dynamics: Empirical investigation and simulation. In Proceedings of Measuring Behavior, 2012. 